\title{
Determinants trigger Vietnamese young consumers to purchase eco-friendly products
}

\author{
Tran Thi Bach Yen ${ }^{a^{*}}$, Huynh Thi Cam Ly ${ }^{\mathrm{b}}$ and Nhung Hoang ${ }^{\mathrm{c}}$
}

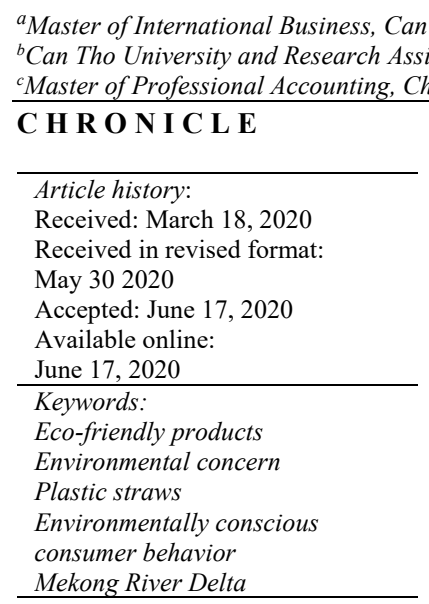

(C) 2020 by the authors; licensee Growing Science, Canada

\section{Introduction}

There is a greatly growing attention to tackle plastic pollution issues. Previous studies proposed various instruments dealing with the plastic problems. Education and information programs are frequently used and examined as a mean of promoting pro-environmental behaviour. The United Nations Environment Programme (UNEP) estimates that there are more than 1 million plastic cups consumed every minute, more than 5.000 billion plastic bags produced, and approximately 300 million tons of plastic wastes released every year in the world. According to the estimation of World Bank (WB), in Vietnam, economic losses caused by water pollution has been about 287 million US dollars, and air pollution has inflicted the economic losses of 10 billion US dollars. The literature has revealed a growing number of studies examining behavioral and economic tools for reducing plastic use. Several studies attempted to measure and examine the relationship between environmental knowledge, attitude, perceived consumer effectiveness and self-reported pro-environmental behavior (Vicente-Molina, Fernández-Sáinz, \& Izagirre-Olaizola, 2013; Whitmarsh \& O'Neill, 2010). While environmental education has been commonly used, studies using environmental education (EE) packages mostly focused on improving knowledge and perception of the observed individuals toward environmental issues (Hoang \& Kato, 2016). For that situation, a wave of boycotting single use plastic items, particularly plastic straws and plastic glasses, has been strongly rising, originating from videos and images of marine creatures stuck in plastic wastes posted social media; which has formed trends such as \#NoStrawChallenge, \#ZeroWaste, \#ChallengeForChange,... as well as various bans on using single use plastics from European countries, Korea, Panama, the US, and Canada. In order to reduce the significant amount of plastic wastes, many studies have been accomplished about consumers' behavior and their awareness of Eco-Friendly products. Recently, plastic straw products are replaced by bamboo straws, grass straws, paper straws, stainless steel straws and even rice straws which gradually gains the market share by a part of consumers, especially the young ones. A question which arises, is whether the * Corresponding author.

E-mail address: ttbyen@.ctu.edu.vn (T. T. B. Yen)

(C) 2020 by the authors; licensee Growing Science, Canada doi: $10.5267 /$ j.msl.2020.6.023 
behavior of using alternatives to plastic straws is a temporary trend which are impacted by media and crowd psychology, or it comes from the awareness and consciousness of environmental protection; which factors influence the consumers' intention of using environmentally friendly products? Therefore, investigating this matter is incredibly necessary and urgent in the real situation of environmental pollution at alarming levels in Vietnam in general and Mekong Delta area - in particular to have proper orientations in the propaganda of environmental protection as well as to meet the customers' current trends.

\section{Literature review}

\subsection{Theoretical background}

Green products' definition, according to Shidiq and Widodo (2018), is defined as environmentally friendly products which are manufactured and processed in a way that reduces the impacts that may cause environment contamination during production, distribution, and consumption processes. However, according to Ottman et al. (2006), any consuming products always have negative impacts on the environment at different levels. This means that there are currently no products which are absolutely friendly with the environment and only relatively environmentally friendly products exist. This is because the process from production, consumption, to disposal of any products has partly influenced the environment. Millennials definition, Millennials, also known as generation Y, is a concept that is used to describe people born between 1980 and 2000 s. According to Heo and Muralidharan (2017), Millennials are divided into Older Millennials (aged from 25 to 33) and Younger Millennials (aged from 18 to 24). There are three reasons why the segmentation of young consumers cannot be ignored regarding green consumption behavior. First of all, previous studies show that young people are more willing to accept new ideas than older generations (Ottman et al., 2006) and people who advocate to protect the environment are often the younger ones (Martinsons et al., 1997). Secondly, the segmentation of young adults is accounting for a huge proportion of the market's expenditure and is expected to become powerful consumers, making this segmentation a top target for marketers (Heo \& Muralidharan, 2017). Thirdly, buying decision of young people are greatly affected by families and friends in a direct or indirect way (Fry, 2015; Caruana \& Vassallo, 2003; Kaur \& Singh, 2006; Shim, 1996; Shoham \& Dalakas, 2005; Singh et al., 2003). Consequently, this study mainly focuses on groups of people aged between 18 and 33 that are highly aware of environmental issues (Shoham \& Dalakas, 2005), largely affected by families and friends towards green consumption behavior (Muralidharan et al., 2016), and are willing to recommend environmentally friendly products to their friends if the price is reasonable and the products are made from recycled materials (Rawashdeh, 2018; Rahmandoust \& Soltani, 2019).

\subsection{Theoretical model}

Many previous studies about green consumption behavior inherited the theory of planned behavior (TPB) of Ajzen (2002) (e.g., Samadi, 2018; Ajina, 2019; Ha, 2020) and this study is based on TPB theory (Ajzen, 2002). By reviewing relevant documents, the author's proposed model that consists of 6 factors which are environment awareness, perceived effectiveness, consumption attitude, subjective norm, media, and perceived behavioral control (See Fig. 1).

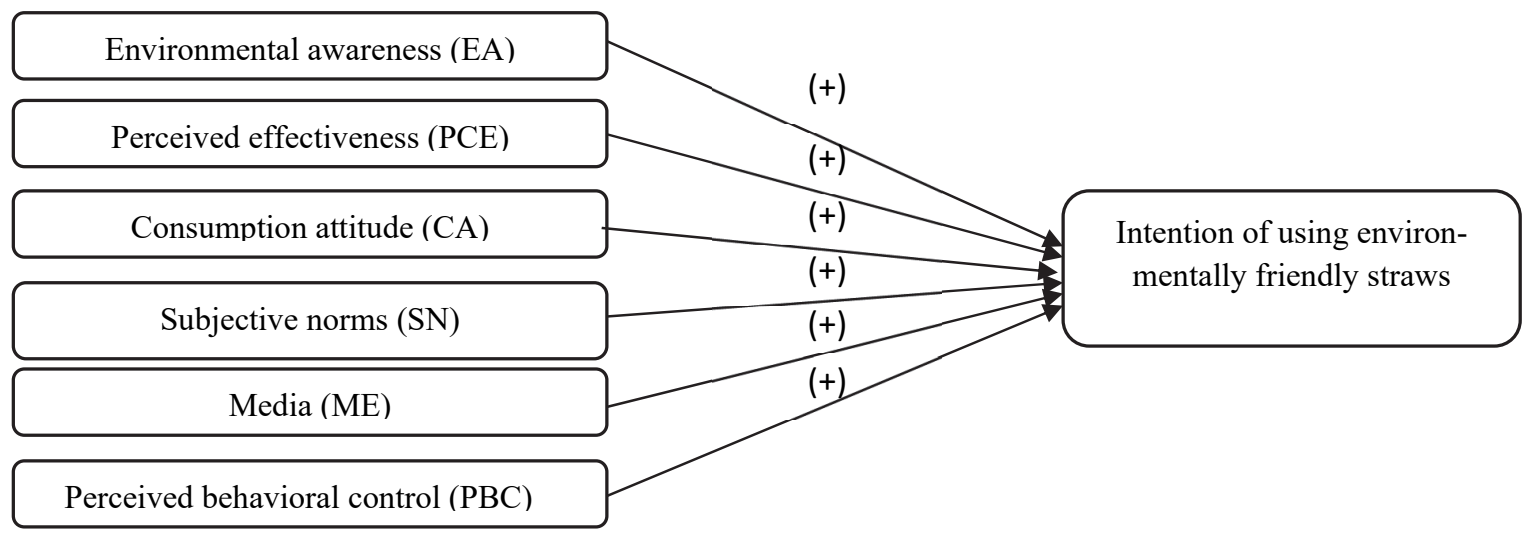

Fig. 1. Theoretical model (Source: Applying theory of planned behavior TPB - Ajzen, 1991)

\subsection{Research methodology}

\subsubsection{Data collection method}

Both primary and secondary data are used in this research. More specifically, secondary data were collected from General Statistic Office, Ministry of Natural Resources and Environment, The United Nations Environment Programme (UNEP), World Bank (WB), and other relevant scientific studies. Primary data were collected by a survey of 150 individuals aged from 18 to 33 in MRD city through a questionnaire. The sample size is specified based on approaching the Exploratory Factor Analysis, and the linear regression is used in the study. According to Suhr (2006), the number of observations in the Exploratory Factor Analysis method must be at least 5 times the number of observed variables in the factor analysis. In addition, as maintained by Tabachnick and Fiddeel (1996), the minimum observed sample size in the linear regression analysis is calculated by the formula $N>50+m$ (in which $m$ is the independent variable). In order to fit the previous studies as well 
as the research model in this research with 26 observed variables and 7 components, the minimum sample size must be $\mathrm{N}=$ $26 \times 5=130$ and $N>50+8 \times 7=106$. As a result, the sample size of 150 observations is demonstrated to meet the requirement of the previous studies. Simultaneously, the research is implemented by non-probability sample size method; because straw products are almost familiar, they ensure the representative of the sample. In which, the survey of this study was conducted in different places in MRD city such as Can Tho University, Can Tho University of Pharmacy and Medicine, Nam Can Tho University, and ACECOOK Joint Stock Company, so as to check the differences in the awareness and the intention to use environmentally friendly straws between the places where single use plastics are prohibited and the places in which single use plastics are not prohibited.

\subsubsection{Data analysis methods}

The study has used the cross-tabulation analysis to test the differences in the awareness and the young consumers' intention to use environmentally friendly straws between the place where single use plastics are prohibited and the place in which single use plastics are not prohibited in MRD cities. With 26 observed variables determined through 6 independent variables and 1 dependent variable, the study has used the Exploratory Factor Analysis (EFA) to group factors that affect the intention to use environmentally friendly straws. Before implementing factor analysis, the scales of the research are tested by Cronbach's Alpha coefficient to eliminate the inappropriate variables. For that reason, linear regression method is used to estimate the influential level of independent variables on dependent variable - the intention to use environmentally friendly straws.

\section{Results}

\subsection{Factors that trigger the intention to use environmentally friendly straws}

The author did a survey on 150 interviewees through 23 criteria of 6 factors that affect the intention to use environmentally friendly straws of young people in the Mekong River Delta.

Table 1

EFA result of factors that affect the intention to use environmentally friendly straws

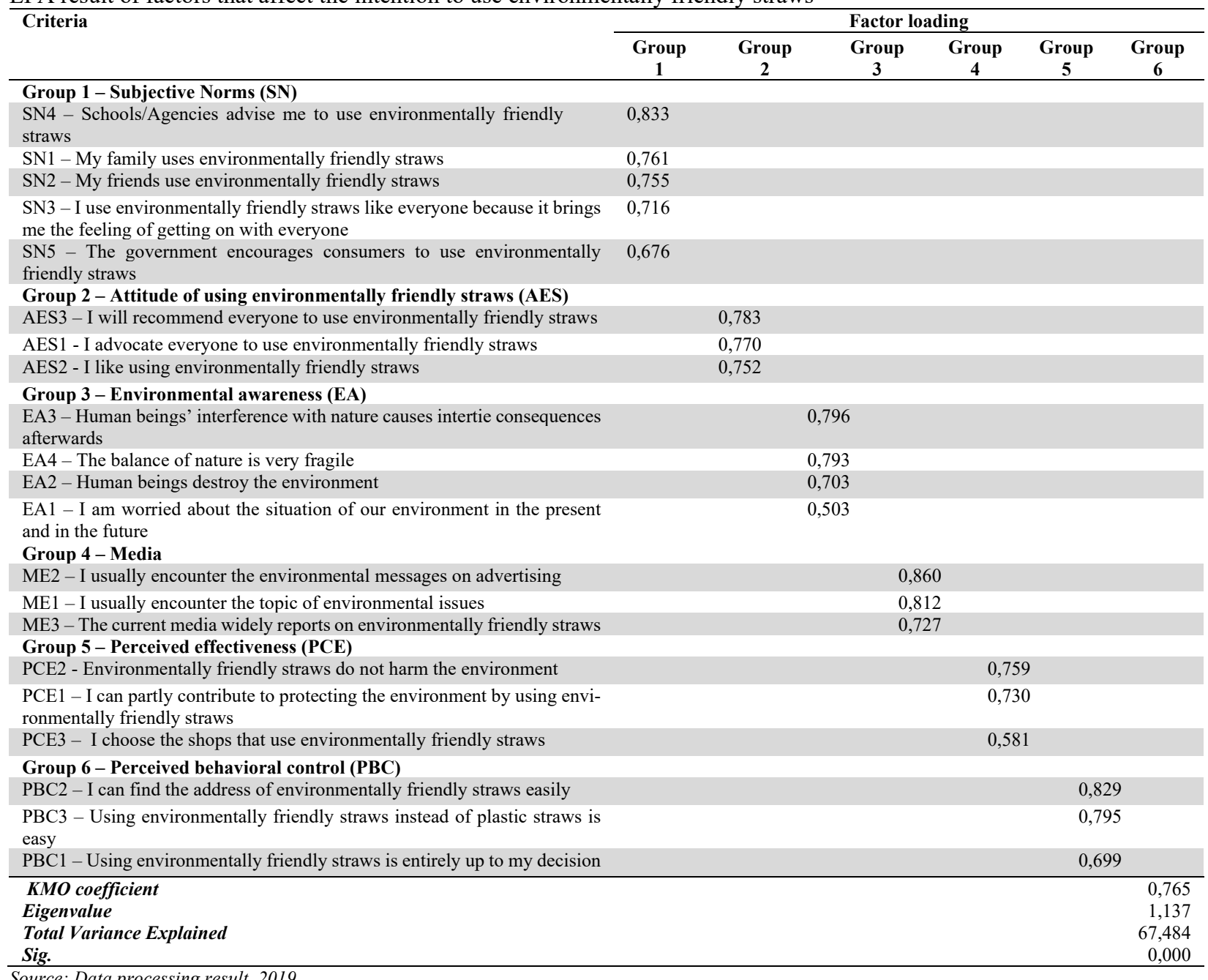


By testing Cronbach's Alpha, the results show that 23 proposed criteria are not eliminated (correlation coefficients are greater than 0,3), which are suitable for conducting the Exploratory Factor Analysis EFA. In the first factor analysis results, the PCE4 criterion, "I feel I am more on the trend when using environmentally friendly straws", is excluded because factor loading is $<$ 0.5. Continuing with the second factor analysis results, the AES4 criterion, "using environmentally friendly straws is really necessary to protect the environment", is also eliminated due to the violation of convergence rules, which means that the maximum and the minimum value are $<0,3$ in the same line. The author continued conducting the third factor analysis and obtained 21 criteria that affect the intention to use environmentally friendly straws. Thus, the result from Table 1 demonstrates that the Exploratory Factor Analysis result totally satisfies the conditions, specifically: (1) testing the appropriateness of the model $(0,5<\mathrm{KMO}=0,765<1,0)$; (2) Bartlett's test of correlation of observed variables $(\mathrm{Sig} .=0,000<0,05)$ confirms that the variables are closely connected; (3) Total Variance Explained equals to $67,484 \%$ variance of data.

\subsection{The intention of using environmentally friendly straws}

Similar to independent variables, the dependent variable - the intention to use environmentally friendly straws - is evaluated through 3 criteria and exploratory factor analysis. The detailed results are shown in Table 2 with: (1) testing the appropriateness of the model $(0,5<\mathrm{KMO}=0,765<1,0)$; (2) Bartlett's test of correlation of observed variables $($ Sig. $=0,000<0,05)$; $(3)$ Total Variance Explained $=74,733 \%(>50 \%)$ satisfies the requirement and the factor loading is greater than 0,5 . To sum up, 3 evaluation criteria are extracted into a common factor and sufficiently meet the requirement; the factor analysis results are perfectly appropriate.

\section{Table 2}

The factor analysis results of the intention to use environmentally friendly straws

\begin{tabular}{ll}
\hline Criteria & Factor loading \\
I $2-$ I intend or continue using environmentally friendly straws & 0,890 \\
$\mathrm{I} 1-\mathrm{I}$ intend to use environmentally friendly straws due to ecological reason & 0,867 \\
$\mathrm{I} 3-$ I intend to recommend my friends and families to use environmentally friendly straws & 0,836 \\
\hline KMO coefficient & 0,711 \\
\hline Eigenvalue & 2,242 \\
Total Variance Explained & 74,733 \\
\hline Sig. & 0,000 \\
\hline
\end{tabular}

\subsection{Analyzing factors that affect the intention to use environmentally friendly straws}

In order to determine the causality, the influential level of the independent variables includes environmental awareness, perceived effectiveness, consumption attitude, subjective norm, media, perceived behavioral control, and the dependent variable - the intention to use environmentally friendly straws. The linear regression results are specifically presented in Table 3 :

Table 3

The linear regression results of independent variables

\begin{tabular}{|c|c|c|c|c|c|c|}
\hline Variables & B Coefficient & Standard error & $\begin{array}{c}\text { Beta } \\
\text { Coefficient }\end{array}$ & T-Test & $\begin{array}{c}\text { Significance } \\
\text { Level }\end{array}$ & VIF \\
\hline Constant & $-0,411$ & 0,355 & & $-1,266$ & 0,222 & \\
\hline Environmental awareness (EA) & 0,251 & 0,066 & 0,214 & 3,786 & 0,000 & 1,151 \\
\hline Perceived effectiveness (PCE) & 0,126 & 0,062 & 0,130 & 2,029 & 0,044 & 1,477 \\
\hline Media (ME) & 0,057 & 0,058 & 0,059 & 0,988 & 0,325 & 1,278 \\
\hline Attitude (AES) & 0,386 & 0,064 & 0,408 & 6,045 & 0,000 & 1,648 \\
\hline Behavioral control (PBC) & 0,148 & 0,043 & 0,195 & 3,445 & 0,001 & 1,155 \\
\hline Subjective norm (SN) & 0,154 & 0,053 & 0,168 & 2,895 & 0,004 & 1,220 \\
\hline$R^{2}$ & & & & & & 0,605 \\
\hline Adjusted $R^{2}$ & & & & & & 0,588 \\
\hline Sig.F & & & & & & 0,000 \\
\hline Durbin - Watson coefficient & & & & & & 2,138 \\
\hline
\end{tabular}

From Table 3, the $\mathrm{R}^{2}$ value equals to 0,605 which means that the model explains $60,5 \%$ of the variable value of independent variables that impact on dependent variable; the remaining 39,5\% is for the out-of-model variables and random errors. Simultaneously, Durbin - Watson coefficient (d) $=2,138$ (approximately equals to 2) means there is no autocorrelation phenomenon; VIF value of factors are all smaller than 10 , so there is no multicollinearity phenomenon; Sig.F coefficient $=0,000<0,05$ proves that the research model is in accordance with the data. From the regression results in Table 3 , in 6 factors mentioned that affect the intention to use environmentally friendly straws, media (ME) is excluded due to the significance level Sig. $>0,05$. Similar to other results, media has a very low impact on the research model. This is because the propaganda activities and advertising via the Internet, newspapers, television,... are just slogans, which are not emotional messages, so it is hard to attract viewers' attention and altruism. Then, from the regression analysis results on regression model of 5 remained independent variables, the following equation is proposed: 


$$
Y=-0.411+0.251 E A+0.126 P C E+0.386 A E S+0.154 S N+0.148 P B C
$$

The regression shows that the regression coefficients are all greater than 0 ; as a result, it can be concluded that independent variables have positive impacts on the dependent variable; in which, based on the magnitude of unstandardized regression coefficients Beta variable, the most influential factor on the intention to use environmentally friendly straws is consumption attitude (AES), followed by environmental awareness (EA), subjective norm (SN), perceived behavioral control (PBC), and perceived effectiveness (PCE) is the last one.

\subsection{Some solutions that promote the intention to use environmentally friendly straws of young people in Mekong River Delta}

Raising consumers' awareness and mind-set, the research results demonstrate that consumers' attitude has positive impacts on the intention to use environmentally friendly straws, which is also the most influential factor that affects the intention to use environmentally friendly straws. Throughout practical activities, forums, and information on media (social media, websites, e-newspapers,...) in terms of this matter, consumers will be able to understand that their actions positively impact on the environment; once they have the positive attitude, they will support and recommend their friends, colleagues, and relatives to use environmentally friendly straws. Additionally, the research results show that more than $37 \%$ of consumers suppose that plastic straws have trivial impacts on their health. Consequently, the propaganda activities regarding origin of production and the harmful effects of plastic straws on humans and natural environment should be strengthened in order to raise consumers' awareness of reducing plastic straws in daily life.

Offering various distribution locations that sell environmentally friendly straws, one of the most challenging barriers that affects the intention to use environmentally friendly straws is that it is difficult for consumers to look for the places which sell environmentally friendly straws. That is the reason why advertising on social media, websites, and e-newspaper is necessary; besides, diversifying the distribution channels, not only supermarkets but also beverage shops, is also a good way.

Regulations of banning single use plastics, the research results clarify that compared to places where single use plastics are not banned, consumers have both higher intentions to use environmentally friendly straws and better awareness of environmental issues in places that single use plastics are prohibited. Apparently, agencies and schools have effectively enacted the regulations to reduce the plastic wastes and form the organization's culture; which not only directly influences the organization's members, but it also inspires their friends, colleagues, and even relatives. To sum up, the enactment of regulations for banning single use plastics has brought many positive effects; however, it is necessary to have the unification among the organization's departments in order to avoid the spontaneous programs. This is because unless the ban on single use plastics is controlled, effectively implemented, and remained in long-term, it can cause many consequences afterward. Taking Bangladesh as an example, although the policy of banning single use plastics was enacted in 2002, Bangladesh has ranked $10^{\text {th }}$ in terms of the amount of plastic wastes released to the oceans owing to the loose control and lack of alternatives, which makes the ban invalid as expected.

\section{Conclusion and managerial implications}

The study has focused on evaluating the awareness and behavior of using environmentally friendly straws of young people in MRD. The research results have shown that most consumers are aware of how harmful the plastic straws are to the environment and humans' health. Nevertheless, a part of consumers did not agree to eliminate plastic straws entirely since the advantages of environmentally friendly straws cannot be replaced by the convenience and the strengths of plastic straws. There is an option that a large part of consumers chooses to pay for plastic straws in beverage shops, yet this solution is not feasible. Using environmentally friendly straws should originate from consumers' awareness and their responsibility in protecting the environment. Throughout the survey results, factors that affect the intention to use environmentally friendly straws are: (1) Attitude; (2) Environmental awareness; (3) Subjective norm; (4) Perceived behavioral control; (5) Perceived effectiveness; in which, the most influential factors triggered on the intention of using eco-friendly straws are users' attitude and behavior, followed by environmental awareness, subjective norm, perceived behavioral control, and perceived effectiveness. The study also demonstrates that in places where single use plastics are banned, consumers have better awareness and higher intention to use environmentally friendly alternatives than in places where single use plastics are not banned. To sum up, people aged from 18 to 33 in MRD city are all aware of the environment and caring for current environmental problems. For a large part of consumers, they are willing to accept the disadvantages of environmentally friendly straws in order to contribute to protecting the environment, reducing the amount of plastics wastes in the world in general and in Vietnam in particular. They are greatly influenced by the rules and culture of their organizations where they are participating in; then they influence their friends, colleagues, and families. It can be stated that this is the greatly potential consumer group in using environmentally friendly products, particularly environmentally friendly straws.

\section{References}

Ajina, A. (2019). Predicting customers' online word of mouth intention: The theory of planned behavior applied to understand youth Saudi social media behaviors. Management Science Letters, 9(10), 1553-1566. 
Ajzen, I. (2002). Perceived behavioral control, self-efficacy, locus of control, and the theory of planned behavior 1. Journal of Applied Social Psychology, 32(4), 665-683.

Caruana, A., \& Vassallo, R. (2003). Children's perception of their influence over purchases: the role of parental communication patterns. Journal of Consumer Marketing, 20(1), 55-66.

Fry, R. (2015). Millennials surpass Gen Xers as the largest generation in US labor force. Pew Research Center, 11.

Ha, N. (2020). The impact of perceived risk on consumers' online shopping intention: An integration of TAM and TPB. Management Science Letters, 10(9), 2029-2036.

Heo, J., \& Muralidharan, S. (2019). What triggers young Millennials to purchase eco-friendly products?: the interrelationships among knowledge, perceived consumer effectiveness, and environmental concern. Journal of Marketing Communications, 25(4), 421-437.

Hoang, T. T. P., \& Kato, T. (2016). Measuring the effect of environmental education for sustainable development at elementary schools: A case study in Da Nang city, Vietnam. Sustainable Environment Research, 26(6), 274-286.

Kaur, P., \& Singh, R. (2006). Children in family purchase decision making in India and the West: A review. Academy of marketing science review, 8,1 .

Martinsons, M. G., So, S. K., Tin, C., \& Wong, D. (1997). Hong Kong and China: emerging markets for environmental products and technologies. Long Range Planning, 30(2), 277-156.

Muralidharan, S., Rejón-Guardia, F., \& Xue, F. (2016). Understanding the green buying behavior of younger Millennials from India and the United States: A structural equation modeling approach. Journal of International Consumer Marketing, 28(1), 54-72.

Ottman, J. A., Stafford, E. R., \& Hartman, C. L. (2006). Avoiding green marketing myopia: Ways to improve consumer appeal for environmentally preferable products. Environment: Science and Policy for Sustainable Development, 48(5), 22-36.

Rahmandoust, A., \& Soltani, R. (2019). Designing a location-routing model for cross docking in green supply chain. Uncertain Supply Chain Management, 7(1), 1-16.

Rawashdeh, A. (2018). Examining the effect of green management on firm efficiency: Evidence from Jordanian oil and gas industry. Management Science Letters, 8(12), 1283-1290.

Samadi, S. (2018). Theory of planned behavior and knowledge sharing among nurses in patient computer management system: The role of distributive justice. Management Science Letters, 8(5), 427-436.

Shidiq, A.M.N., \& Widodo, A. (2018), Green product purchase intention: Impact of knowledge and green attitude. Jurnal Sekretaris dan Administrasi Bisnis, 2(2), 60 -73.

Shim, S. (1996). Adolescent consumer decision-making styles: The consumer socialization perspective. Psychology \& Marketing, 13(6), 547-569.

Shoham, A., \& Dalakas, V. (2005). He said, she said... they said: parents' and children's assessment of children's influence on family consumption decisions. Journal of Consumer Marketing, 22(3), 152-160.

Singh, N., Kwon, I. W., \& Pereira, A. (2003). Cross-cultural consumer socialization: An exploratory study of socialization influences across three ethnic groups. Psychology \& Marketing, 20(10), 867-881.

Suhr, D. D. (2006). Exploratory or confirmatory factor analysis?

Tabachnick, B. G., \& Fidell, L.S. (1996). Using multivariate statistics (3rd ed.). New York: HarperCollins.

Tran, N.C. (2006). Universities as drivers of the urban economies in Asia: The case of Vietnam. The World Bank.

Vicente-Molina, M. A., Fernández-Sáinz, A., \& Izagirre-Olaizola, J. (2013). Environmental knowledge and other variables affecting pro-environmental behaviour: comparison of university students from emerging and advanced countries. Journal of Cleaner Production, 61, 130-138.

Whitmarsh, L., \& O'Neill, S. (2010). Green identity, green living? The role of pro-environmental self-identity in determining consistency across diverse pro-environmental behaviours. Journal of Environmental Psychology, 30(3), 305-314.

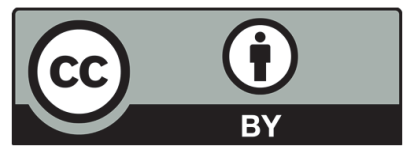

(C) 2020 by the authors; licensee Growing Science, Canada. This is an open access article distributed under the terms and conditions of the Creative Commons Attribution (CC-BY) license (http://creativecommons.org/licenses/by/4.0/). 